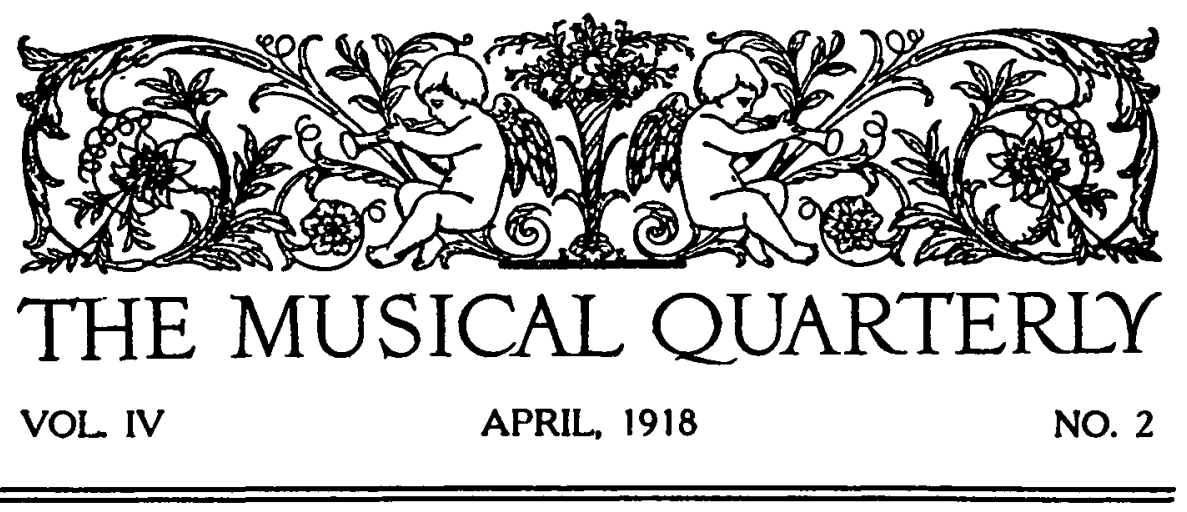

\title{
REPRESENTATIVE MUSIC
}

\author{
By E. SAPIR
}

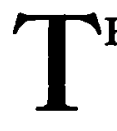

HE contest between the absolutists and the supporters of "programme" in modern music has often been characterized by extreme and mutually irreconcilable attitudes. On the one hand we have the purists or formalists, who either explicitly deny or evade acknowledgment of any necessary relation between musical forms and states or functions of mind occurring in other than musical experience. To these a sonata or even a bare musical "theme" is esthetically satisfying by virtue of its own inherent beauty of melody, rhythm, harmony, construction, or color, quite regardless of any non-musical "meaning" it may be thought to possess. Such people would be annoyed rather than helped by the interpretation of a certain Beethoven sonata as suffused by a spirit of moonlight pensiveness. Why mar the sheer beauty of a self-sufficing art-form by attaching to it a label of extraneous origin?

No less decided are some of the "programme" enthusiasts. While not denying to melody, rhythm, and the other means of musical expression an inherent sensuous beauty, and to musical construction the essential beauty of all design, they maintain that the enjoyment of such merely sensuous or structural beauty is an æsthetic one only in a more or less elementary phase. To a piece of music must, properly speaking, be denied the term artform in its highest sense unless it does more than tickle our sense of rhythm or color or evoke our admiration by its skilful handling of the purely formal aspect of the musical problem. It must have vitality (to use a much abused word), that is, it must be associated in the mind of both creator and public, and this by virtue of its intrinsic quality, with some element or elements in their experience. 
It dare not stand coldly aloof, on pain of degenerating into clever trifling, from the more definitely articulated currents of life, but must seek to gain in significance, and therefore in æsthetic value, by embodying, in its own peculiar way, one or more of the incidents or phases of that life. The nature of such embodiment may vary indefinitely. In some cases the music may be content to picture a mood, in others to catch some aspect of nature, in others to define an idea, in still others to mark a succession of moods or ideas that in their totality comprise a "story."

The progress of musical art is thus toward ever increasing complexity and definiteness of emotional and conceptual expression. In other words, music must tend to be "representative" in character. Music has lagged far behind plastic art and poetry in this respect, but this is due primarily to the great lapse of time which it has taken the art to develop a technique rich and flexible enough to fulfil its higher mission.

If the history of esthetic criticism teaches us anything, it is the futility of trying to mark off the legitimate province of an art or an art-form. Over and over again a critic has demonstrated, to the complete satisfaction of the discerning, certain inherent resthetic limitations. He proved his point, but some genius has generally managed to override his formula and consign it to the dust-bin of things that were. My own aim is, therefore, not the presumptuous one of a definition of the proper sphere of music but rather an attempt to state what music seems to me best able to accomplish.

To begin with, can the absolutists really succeed in eliminating an emotional substratum, of varying vividness, from the appreciation of a musical composition? I do not refer to the emotional components of musical appreciation that are evident in the enjoyment of any of the elements of musical expression as such (such as pleasure in certain instrumental combinations or delight in the recurrence of a well-defined rhythmic figure or the more subtle pleasure derived from consideration of a certain balance of form), but only to a mood or attitude of mind induced by the composition as a whole and to which the former types of pleasure must normally be considered as subsidiary. As a matter of fact, it is difficult to listen to one of the greater compositions even of pre-programme days without finding ourselves put into a rather definite mood, a mood which to all intents and purposes defines the meaning of the music for us. And does not the verdict of the present in judging of the relative merit or appeal of musical works of the past often clearly imply just such an emphasis on 
the æsthetic importance of definite emotional quality? Thus, it is no exaggeration to say that most of the Mozart sonata movements, despite their spontaneous flow of melody and finish of external form, are of lesser æsthetic value to us than many of the simply constructed Bach preludes of the "Well-tempered Clavichord." These preludes belong to a remoter period of musical history, but their deep-felt, though restrained, quality of emotion, (think of the devotional spirit of the very first prelude manifest enough without the Gounod Ave Maria pendant; or of the mood of serene sadness that permeates the beautiful $\mathrm{E}$ flat minor prelude of the first set) keeps them alive where the Mozart sonatas, on the whole, must be regretfully admitted to have become a respectable and faded musical tradition. Craftsmanship, no matter how pleasing or ingenious, cannot secure a musical composition immortality; it is inevitably put in the shade by the technique of a later age. True, such craftsmanship may be admirable, as a dynamo or a well played game of billiards elicit admiration; yet admiration does not constitute resthetic enjoyment.

Aside from the emotional substratum which we feel to be inseparable from a truly great and sincere work of musical art, are there not in the earlier supposedly absolutist art plenty of instances of direct realistic suggestion, sometimes intentional, no doubt, at other times a spontaneous product of association on the part of the listener? Is it possible, for instance, to listen to certain of the Beethoven scherzos without sensing the gambling faun (or convention-freed ego) kicking his heels with a relish? But Beethoven, the idol of the absolutists, was no more an absolutist than Aristotle, the idol of the scholastics, was a scholastic. I do not think it would be going too far to say that all musical art worthy of the name has implicitly, if not avowedly, some of the fundamental qualities of so-called "programme" music; from a musical standpoint it should make little difference whether the emotional appeal is left to declare itself in the mind of the sympathetic listener or is trumpeted at him by means of a formidable printed analysis.

We have turned our backs on the uncompromising absolutist. Are we therefore to receive his most uncompromising opponent with open arms? I have already indicated in a general way the aims and procedure of representative music. It either uses all of its technical resources to define a mood or emotion, or it may, by the use of some special element of technique or combination of such elements, depict a selected feature of the external world 
(rapid passage work may be utilized to symbolize the flowing brook or the falling rain or the roaring wind, the high pitched piccolo tones may do service for the shrieking of the tempest or the chirping of birds, the loud discord of clashing harmonies may suggest a battle scene or the clangor of a foundry). Now there seems to me to be a profound psychological difference between those two types of procedure, intertwined as they necessarily often are in practice. That the former touches our emotional life while the latter plays upon our sense experience is obvious. The distinction I have in mind is more deep-seated. Realistic suggestion must make use of the principle of association, and the fact of such association becomes obvious to the listener on reflection. By the musical equivalent of a figure of speech, a feature common to two otherwise totally dissimilar phenomena (the thing symbolized and a certain mass of sound) is made to identify them. If, for some reason or other, the experience of the auditor has been such as not to make the association obvious, the suggestion loses all its force and the artist, insofar as he is writing merely representative music, has with that auditor failed of success. On the other hand, music is able to put us into more or less well defined emotional states without such associative intermediation, or, perhaps more accurately, the associative links are of so obscure and intimate a nature as never to rise into consciousness. In other words, the emotional effect of music is gained directly or, what amounts to essentially the same thing, gives the impression of being so gained. Once this point is clearly grasped, it becomes obvious that the function of music, insofar as it has resthetic aims of other than a sensuous and formal nature, is primarily the expression of the emotional aspect of consciousness, only in a very secondary sense the expression of the conceptual aspect. This primary function is thus of poetic quality and may be briefly described as the interpretation of emotional quality in terms of sensuous and structural beauty. A still more concise way of putting the matter is to define music as an idealization of mood by means of tone.

It has often been instinctively felt that music which makes too free a use of realistic suggestion lays itself open to the charge of superficiality, of the abandonment of its own highest artistic capabilities. Even the greatest composers, in its employment, seem often to sail between the Scylla of triviality and the Charybdis of absurdity. And yet there is no doubt that it is capable of affording keen rsthetic pleasure. Probably the simplest and most fundamental element in such pleasure is the sheer delight 
that the mind seems to find in generalizing by analogy, in meeting familiar friends in new and unexpected guise; it is the tonal correspondent of the childish phantasy that interprets cloud shapes as battleships and monsters and human faces. More careful analysis, however, shows that this type of pleasure is, in the best examples of musical suggestion, powerfully reinforced by another though not always clearly distinct factor. The melodic, harmonic, rhythmic, or other musical idea which serves as the symbol of the concept represented has in such cases an independent sensuous beauty of its own, a beauty whose appeal transcends our normal interest in the concept itself. Hence such music amounts to an idealization of some aspect of the external world. To our greeting of a friend in disguise is added the much greater pleasure of finding him transported to a higher plane of being. And this brings us to a third and yet more significant phase in the use and appreciation of realistic suggestion, that in which the concept is not idealized for its own sake, is not merely represented as such, but is utilized as a symbol of the emotion simultaneously called forth by the music. Obviously this means a very considerable heightening of the quality of the emotion itself. The finest examples of realistic suggestion derive much of their charm from this very factor. In other words, realistic suggestion in music is most successful when it ceases to be merely what its name implies but contributes to the enrichment of the emotional aim of music. Thus even in so obviously suggestive a bit of music as the delightful "Jardins sous la pluie" of Debussy, the secret of the appeal, it seems to me, lies not so much in the clever devices of rhythm, melodic progression, and shading which symbolize the pitter-patter, the gustiness, the steady fall, and the tempestuous downpour of the rain as in the delicate and wistful line of emotion that runs through the composition; the rain but voices human feeling. And such humanizing of the external world via emotion is a significant indication of the primary function of musical art.

We have just seen that realistic suggestion may assist in the definition of the mood (thus, the suggestion of the shepherd's pipe may reinforce a mood or atmosphere of rustic peacefulness, a dancing rhythm of break-neck rapidity may accentuate a mood of reckless gaiety). In representative music, however, the emotion created by the music is conversely often employed to suggest an associated concept, concrete or abstract. When a certain harmonic progression, for instance, in one of Strauss's tone poems is used to symbolize a mountain, it is clear that the only 
associative link is furnished by the feeling of all-embracing massiveness suggested by the chords in relation to each other (I say "all-embracing," for a feeling of vast extension would seem to be implied in the sudden chromatic modulation at the close of the figure, the immediate juxtaposition of two harmonically remote keys being the musical equivalent of a bringing together of the widely removed in space; the feeling of "massiveness" is conveyed by the use of full compact chords in the bass). My claim here is that, considering the music itself as our starting point, the interpretation suggested by the composer is by no means the only justifiable one, psychologically speaking. Adopting the formula of "all-embracing massiveness" as expressing the quality of emotion conveyed by the passage in question, it seems clear that a quite unlimited number of alternative interpretations are possible (the vastness of the sea, Mother Earth, grim fate, eternal justice), each conditioned by considerations of personal interest and experience in the auditor. If the conceptual interpretation of a single musical passage of definite emotional quality is thus multiform without limit, how much more must this be the case with the conceptual interpretation of a series of such passages, in other words of an extended musical composition! The "story" which we are expected to read in a composition of the "programme" type must be considered as relevant only insofar as it conveniently summarizes in conceptual terms the emotional stream immediately expressed by the music. As such it may be highly welcome. Whether the composer wills it or not, the particular story suggested by his title or analysis is only a more or less arbitrary selection out of an indefinitely large number of possible conceptualizations. We cannot refuse him the right to his own interpretation, to be sure; no more can he refuse each one of us the right to his. All he has done or can do, aside from the possibility of direct realistic suggestion, is to determine for us the character and sequence of our moods. He may modestly direct attention, by means of his programmatic apparatus, to the conceptual genesis in his own mind of this emotional stream or, probably more often than is generally thought, to his own merely secondary interpretation thereof, but he cannot via a non-conceptualizing medium, i. e. music, force any particular stream of thought on us except insofar as we surrender into his hands our own individuality of judgment and association. In short, the music does not "tell" the story but the story tells or rather guesses at the music. If the composer absolutely must appeal conceptually, as well as emotionally, to his hearers, he must have recourse to 
the conceptual implement which society has evolved, i. e. language. In other words, he must supplement his own expression of emotion by calling in the aid of the poet. His art then takes on the special forms of the song, music drama, oratorio.

I have said that all the composer can do is "to determine for us the character and sequence of our moods." It is not worth while for him to aim at a purely representative ideal; his highest success in this direction will fall miserably short of what is attained by the merest balderdash in literature. In the expression of the emotions, however, he has a field the unending fruitfulness of which is hardly realized by most people. We think it a field of narrow range because words, mere conceptual symbols, are lacking to indicate its infinite nuances. Select a half dozen musical examples of the expression of any typical emotion, say unbridled mirth or quiet sadness or poignant anguish, and compare them. The feelings they arouse in us are identical only when translated into the clumsy conceptual terminology of language. In actual fact they will be found to be quite distinct, quite uninterchangeable. It is literally true that the aesthetic expression of mood in tone is an exhaustless field of humian endeavor. Does not the very potency of music reside in its precision and delicacy of expression of a range of mental life that is otherwise most difficult, most elusive of expression? Nay more, does not music ofttimes create nuances of feeling, nuances that add in profound measure to the more external enjoyment of its own sensuous and formal beauty? 